\title{
Atores e impactos na reestruturação do espaço urbano de Imperatriz-MA: observações a partir da implantação da Suzano Papel e Celulose (2008-2015)
}

Actors and impacts on restructuring the urban space of Imperatriz-MA: observations from the implementation of Suzano Papel e Celulose (2008-2015) Actores e impacto en la reestructuración del espacio urbano de Imperatriz-MA: Observaciones a partir de la implantación de Suzano Papel e Celulose (2008-2015).

Acteurs et impacts de la restructuration de l'espace urbain, à Imperatriz (Maranhão) : remarques élaborées à partir du cas de l'implantation de l'entreprise Suzano Papel e Celulose (2008-2015)

\section{Allison Bezerra Oliveira and Amanda Araújo Nascimento}

\section{(2) OpenEdition}

Electronic version

URL: http://journals.openedition.org/espacoeconomia/4281

DOI: 10.4000/espacoeconomia.4281

ISSN: 2317-7837

\section{Publisher}

Núcleo de Pesquisa Espaço \& Economia

\section{Electronic reference}

Allison Bezerra Oliveira and Amanda Araújo Nascimento, « Atores e impactos na reestruturação do espaço urbano de Imperatriz-MA: observações a partir da implantação da Suzano Papel e Celulose (2008-2015) », Espaço e Economia [Online], 13 | 2018, Online since 28 November 2018, connection on 14 November 2019. URL : http://journals.openedition.org/espacoeconomia/4281 ; DOI : 10.4000/ espacoeconomia.4281

This text was automatically generated on 14 November 2019 .

(C) NUPEE 


\section{Atores e impactos na reestruturação do espaço urbano de Imperatriz-MA: observações a partir da implantação da Suzano Papel e Celulose (2008-2015)}

Actors and impacts on restructuring the urban space of Imperatriz-MA: observations from the implementation of Suzano Papel e Celulose (2008-2015) Actores e impacto en la reestructuración del espacio urbano de Imperatriz-MA: Observaciones a partir de la implantación de Suzano Papel e Celulose (2008-2015).

Acteurs et impacts de la restructuration de l'espace urbain, à Imperatriz (Maranhão) : remarques élaborées à partir du cas de l'implantation de l'entreprise Suzano Papel e Celulose (2008-2015)

Allison Bezerra Oliveira and Amanda Araújo Nascimento

\section{Introdução}

1 A reestruturação urbana é um fenômeno social que tem sido objeto de estudo no Brasil desde as transformações da economia, com a descentralização industrial, no início da década de 1970. Ela afeta a produção e a organização do espaço construído da cidade, alterando sua estrutura, morfologia e funções internas. Com o processo histórico de reestruturação do capital, as cidades são progressivamente convidadas a participar do movimento de reprodução capitalista do espaço, e, no seio dessa dinâmica, suas estruturas físicas e sociais são reorganizadas para atender cada vez mais às lógicas dos atores hegemônicos (SOARES; AMARAL, 1997). 
2 No Brasil, historicamente, tais transformações são visualizadas e estudadas com mais frequência a partir da região concentrada (SANTOS; SILVEIRA, 2001), em especial o eixo Rio-São Paulo, cujos espaços urbanos, ao longo da história, foram bastante reestruturados a partir de lógicas econômicas de produção e consecutiva fluidez de bens, serviços, pessoas e informações. Tais transformações levaram à composição de uma expressiva centralidade urbano-regional no país, como podemos observar no REGIC (2007).

3 Apesar de a materialidade técnica que permite essa fluidez de bens, serviços, pessoas e informações no território ser fruto de sucessivas reestruturações, sendo visualizada com maior intensidade na região concentrada, a globalização dos mercados e sua inerente necessidade de competição e acúmulo em nível global tem forçado as empresas, em economias de escala, a cada vez mais buscarem espaços que lhes permitam modernizar o processo de produção. Com ajuda do Estado, as empresas são convidadas a se instalarem sob a lógica do desenvolvimento e, através de incentivos e vantagens locacionais, impõem seus mecanismos produtivos aos espaços em que se instalam.

4 A cidade como lócus principal das atividades humanas é convocada a reestruturar-se para atender às demandas de novos agentes que nela se instalam e que para ela são atraídos. $\mathrm{Na}$ esteira dessas transformações, que constituem objeto deste artigo, está a Suzano Papel e Celulose, indústria do segmento de papel e celulose, que se instalou no período de 2008-2015 na cidade de Imperatriz, no estado do Maranhão. Tal dinâmica locacional segue os processos de desconcentração industrial em busca de maior potencialidade competitiva, desencadeados na década de 1970 (SUZIGAN, 2000; SANTOS; SILVEIRA, 2001; CANO, 2008).

5 A implantação da Suzano Papel e Celulose tem sido marcada por expressiva reestruturação do espaço urbano local, de forma que parte significativa dos objetos e ações locais é convidada a seguir uma lógica fabril previamente determinada. Nesse processo, estabelece-se uma atividade industrial ordenada, em contraste com a desordem infligida aos atores locais, obrigados a conviver, no epicentro de um discurso desenvolvimentista, com a especulação e a supervalorização imobiliárias, a reconfiguração do território urbano etc.

6 Dessa forma, o estudo aqui apresentado abrange os reflexos da presença da indústria na cidade de Imperatriz como um forte elemento que reorganiza o espaço e atrai novos atores para instalarem-se na cidade e contribuírem para essa reorganização a partir de uma lógica pré-definida. Os atores aqui colocados em destaque são: a indústria em questão e os agentes da especulação imobiliária, atraídos por determinadas dinâmicas. o recorte espacial da pesquisa é o município de Imperatriz, e o recorte temporal compreende o período de implantação da unidade fabril da Suzano Papel e Celulose (2008-2015).

7 Quanto aos aspectos metodológicos, foram realizados levantamentos acerca das novas configurações adotadas pela cidade para atender às necessidades da indústria: dados secundários sobre a criação de bens e serviços, criação de novas áreas habitacionais, número de empreendimentos abertos no período de 2008-2015. Nessa etapa foram aplicadas entrevistas com funcionários da indústria, de imobiliárias e construtoras. Em seguida foram desenvolvidos mapas com o auxílio do software ArcGIS $10.1^{1}$, com a utilização de imagens Landsat 8 RGB do município de Imperatriz, do ano de 2017, junto 
com dados cartográficos do Instituto Brasileiro de Geografia e Estatística (IBGE), do censo de 2010, para visualização das transformações físicas no espaço urbano da cidade.

Assim, além desta introdução e das considerações finais, este artigo está dividido em três tópicos principais. O primeiro deles, de nome Cidades médias: uma revisão da literatura necessária visa falar da importância e influência que tais cidades exercem para atração de investimentos de alto padrão; o segundo, intitulado Indústria de papel $e$ celulose e sua implantação em Imperatriz-MA, aborda como o espaço organizou-se para atender às exigências do empreendimento e às novas atividades econômicas geradas por ele, seguido de materiais e métodos; e, por fim, o último tópico, Reestruturação urbana e investimentos em novas áreas residenciais: da implantação da indústria aos novos agentes imobiliários, trata das novas áreas habitacionais que surgiram pelo crescimento demográfico vivido pela cidade.

\section{Cidades médias: uma revisão da literatura necessária}

Com a expansão do meio técnico-científico-informacional, na década de 1970, no Brasil (SANTOS, 1985), cresceram as discussões sobre as cidades médias e suas funções no meio em que estão inseridas. Tais questões aparecem frequentemente nos debates acadêmicos sobre o espaço urbano, mesmo que não seja o foco principal da discussão. Compreender as características das cidades médias - ainda que não haja consenso sobre os principais elementos que as definem - e suas funções socioeconômicas entram no processo de análise como elemento fundamental para entender as cidades em um contexto nacional cada vez mais global em face das dinâmicas econômicas.

De acordo com Santos e Silveira (2001), essas cidades emergem de uma lógica baseada no maior nível de materialidade técnica no território. Estabelecidas, assim, a partir de uma maior possibilidade de produção, circulação e, consequentemente, expressivo contingente populacional. Tais aspectos contribuem para a construção de relativas ofertas de serviços em uma dinâmica urbano-regional, e, por conseguinte, para a atração de ofertas de outros serviços, apresentando, assim, como consequência dos aspectos em destaque, relativa centralidade urbano-regional, conforme apresentado na teoria dos lugares centrais de Walter Christaller.

11 Através da atração e inserção de novos atores hegemônicos, as cidades médias tendem a se especializar economicamente, no sentido de dinamizar a economia local ou regional dos espaços onde se encontram, transformando o espaço existente, criando novas formas de consumo e exercendo funções específicas no sistema urbano para o desenvolvimento da região. Tudo isso tem uma única finalidade: a reprodução do capital.

12 Sposito (2007) defende que para compreender o grau de importância dessas cidades devem-se avaliar as mudanças que alteram o papel delas em questões econômicas e territoriais, verificar a ação dos agentes na produção do espaço e uso do território, além de estudar as ocorrências dessas transformações, notando as temporalidades e as espacialidades dos fenômenos.

13 Vale lembrar que o que consideramos hoje uma cidade média - entre 100.000 e 250.000 habitantes, segundo o IBGE, - não se enquadra, por exemplo, nas definições da literatura de 1960/1970, segundo as quais, para receber essa classificação, a cidade 
deveria possuir uma população de no mínimo 20.000 habitantes, mostrando, assim, que as variáveis de classificação mudaram ao longo dos anos.

Frisa-se, aqui, que as cidades médias irão variar de tamanho físico e populacional de acordo com a região em que estiverem inseridas. Assim, como já ressaltado, a importância delas estará condicionada às suas relações, regional e nacional, por meio de sua funcionalidade no que se refere ao consumo e oferta de bens e serviços (SILVA; CALIXTO, 2012).

Deste modo, é possível ver essas cidades como espaços estratégicos com vantagens competitivas para as atividades econômicas. Seu papel de intermediadora nas relações sociais, políticas e econômicas faz com que sejam essenciais para a implantação e o desenvolvimento de novas atividades, como a indústria e toda sua cadeia produtiva.

\section{Indústria de papel e celulose e sua implantação em Imperatriz-MA}

16 A cadeia produtiva industrial é composta por etapas consecutivas de transformação de diversos insumos até chegar ao produto final que será comercializado. Além dos insumos básicos, inclui a matéria-prima, máquinas e equipamentos, distribuição, prestadores de serviços, até chegar aos consumidores. Dessa forma, a indústria de papel e celulose inicia seu processo de produção no plantio do eucalipto, seguido de sua colheita que se dá na etapa de extração florestal.

Denomina-se de setor de celulose e papel o conjunto formado pelas seguintes indústrias: de celulose, de papéis e de artefatos de papéis. O conjunto dessas três indústrias, somado às florestas e às indústrias gráficas e de editoração, além dos segmentos distribuidores, vinculados a todas essas indústrias, constituem a cadeia produtiva de celulose e papel.

18 Tal cadeia inicia-se com processos de Pesquisa, Desenvolvimento e Inovação (PD\&I) de novas mudas. Posteriormente, áreas para o plantio, sejam da própria empresa ou arrendadas de parceiros, são utilizadas para o plantio das mudas em sistemas de rotação, visando ao fornecimento integral de matéria-prima. A colheita da plantação envolve mão de obra e maquinário especializados, além do transporte do eucalipto coletado, em geral realizado por empresas terceirizadas; nesse ponto, vias de escoamento são fundamentais. Em seguida, a matéria-prima é levada até a fábrica, que inicia a transformação da pasta de celulose que é comercializada desta forma ou transformada em papel. É importante destacar que parte expressiva da produção da unidade maranhense da Suzano é exportada para o exterior via Porto do Itaqui, localizado na capital São Luís. Essa cadeia está esquematizada na Figura 1. 
Figura - Esquema da cadeia produtiva de papel e celulose

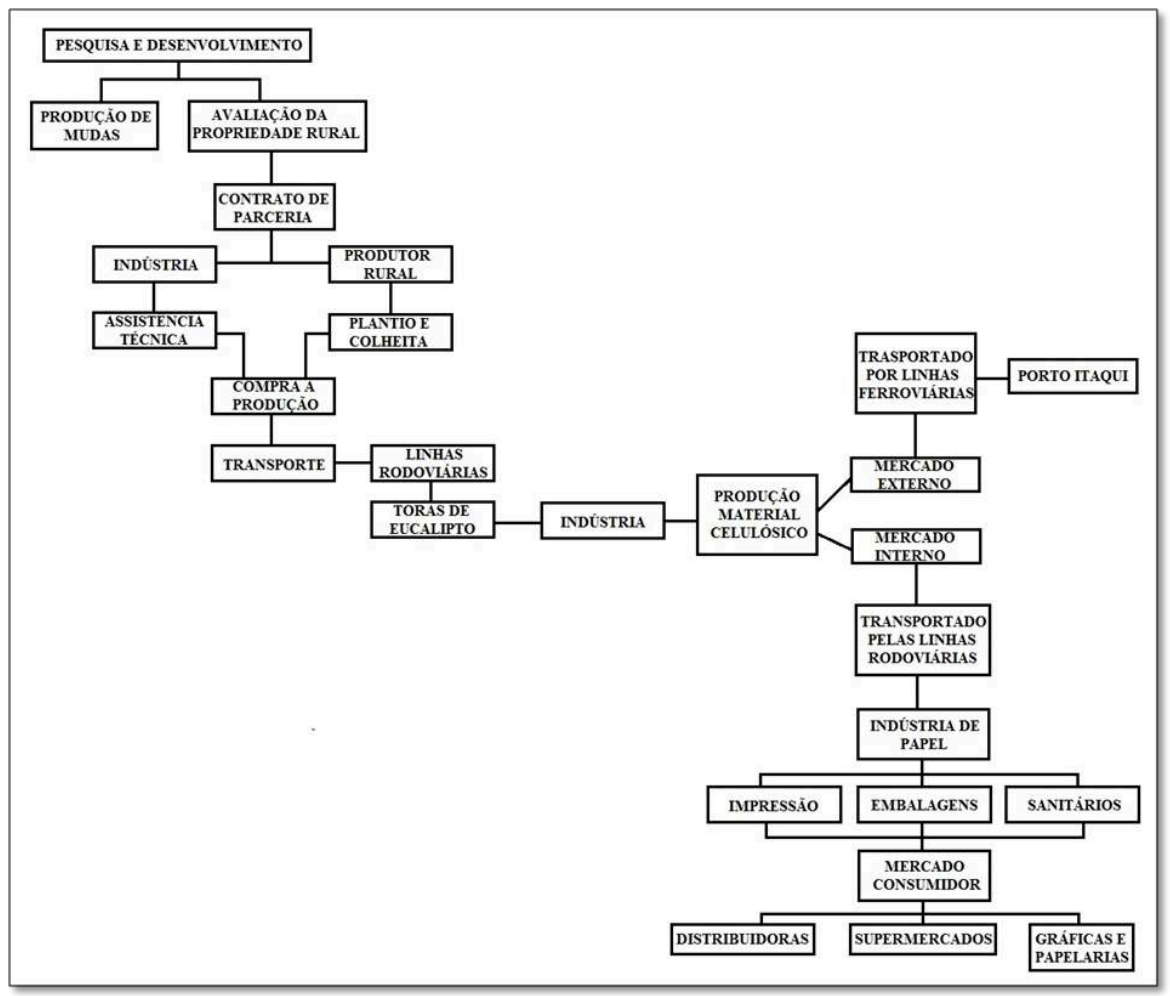

Fonte: Os autores (2018).

19 A indústria brasileira de celulose é composta pelas empresas que produzem celulose e pasta de alto rendimento. Essa polpa pode ser vendida nos mercados doméstico e externo (sendo chamada de celulose de mercado) ou ser usada na produção de papel pela própria empresa que a produz (nesse caso, a polpa é chamada de celulose de integração). Já a indústria de papéis compreende as empresas produtoras de papéis, assim classificados: papéis de imprensa, de imprimir e escrever, de embalagem, sanitários, cartão e para outros fins (Associação Brasileira de Celulose e Papel Bracelpa, 1982-2006).

A cadeia produtiva aqui analisada abrange as etapas de produção de madeira, energia, celulose e papel, reciclagem de papel, produção gráfica e editorial e também atividades de comércio, distribuição e transporte. Esse segmento necessita essencialmente de espaços com grande potencial hidrológico, que permitam o plantio e a colheita de eucalipto, além de infraestrutura e localização geográfica estratégica para o escoamento da produção, construção de fábrica e moradia de funcionários (sobretudo aqueles de maior nível tecnológico ou de responsabilidades, como cargos de gestão ou diretamente ligados à PD\&I).

21 A indústria de papel e celulose, como afirma Leite (1997), passou por um processo, mesmo que tardio, de reestruturação devido às novas demandas concorrenciais e de acumulação econômica global. Nesta lógica buscou-se a inserção de novas tecnologias e de mão de obra com maior nível de qualificação. Iniciou-se também uma busca por fusões e por espaços geográficos com capacidade suficiente de produzir matéria-prima essencial para a produção industrial de papel e celulose, destacando-se, ainda, a busca 
por incentivos fiscais e localização estratégica que facilitasse o escoamento da produção.

No Brasil, os três estados com o maior percentual aglomerativo dessa atividade são: Paraná, São Paulo e Santa Catarina. Encontra-se também alguns outros pontos como Bahia, Rio Grande do Sul, Minas Gerais, Rio de Janeiro e, mais recentemente, o Maranhão, com a cidade de Imperatriz, como apresentado no mapa a seguir.

Mapa - Unidades fabris de celulose e papel no Brasil

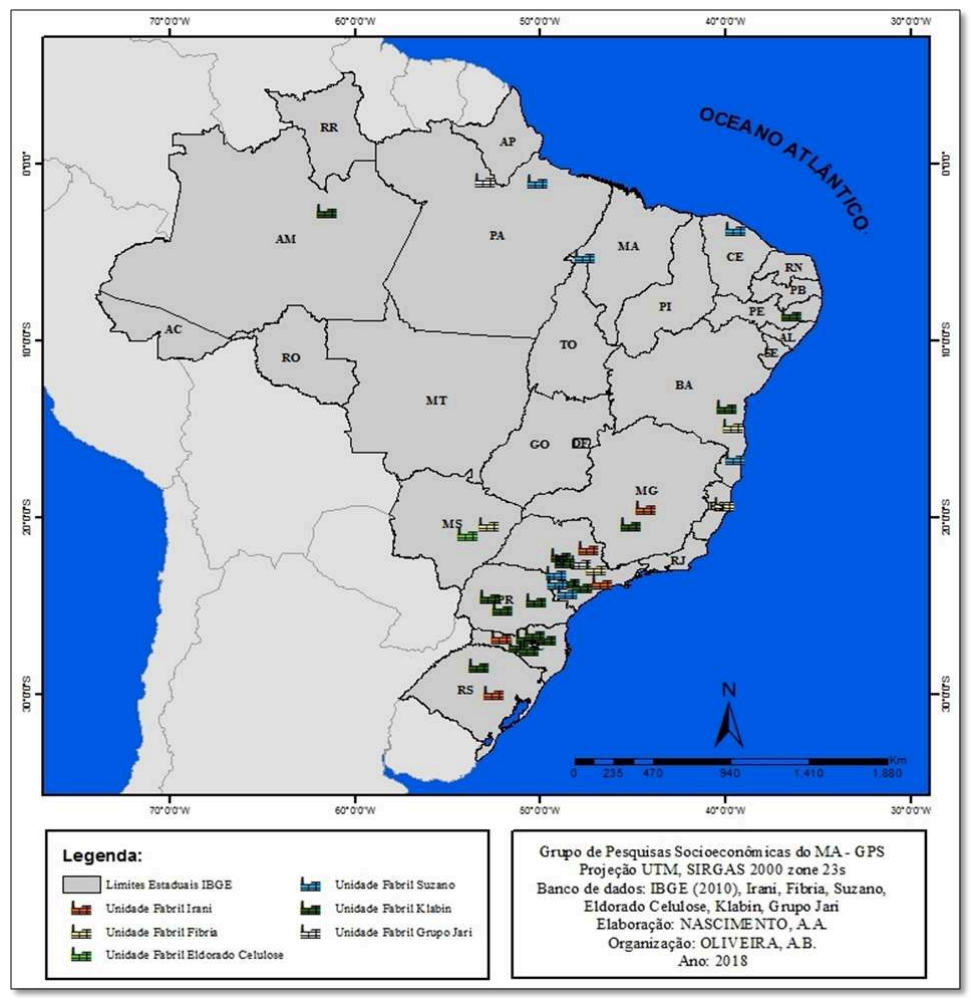

Fonte: Os autores (2018).

O mapa nos mostra que, tradicionalmente, essa atividade industrial estabelecia-se de modo predominante na região concentrada (SANTOS; SILVEIRA, 2001), com breves exceções no caso de Mato Grosso do Sul, Bahia e Pernambuco. Fugindo a essa lógica histórica, deu-se a instalação de uma unidade fabril na cidade de Imperatriz, no estado do Maranhão.

Nesse sentido de reestruturação, as indústrias visam modernizar os modos de produção, e, para tal, convocam outros atores a participarem de suas ações. O Estado, subordinado à atividade industrial em um novo modelo de guerras fiscais, oferece isenções à custa da exploração do espaço e do discurso de desenvolvimento e criação de empregos diretos e indiretos. $O$ espaço de atração fica, então, submetido à lógica de produção e passa a ser reorganizado a partir de uma dinâmica própria que atenda à empresa.

Assim, com o aumento da concorrência econômica capitalista, as empresas - sempre em busca do lucro - aproveitam as condições de espaço favoráveis para sua instalação ou mesmo ofertadas a elas pelo Estado (BOTELHO, 2002). Foram esses padrões que 
incentivaram as grandes empresas a sair dos seus núcleos e partir para locais mais distantes dos grandes centros.

A indústria Suzano, como agente transformador deste caso, iniciou em 2009 seus projetos de instalação em Imperatriz, cidade localizada dentro da microrregião de Imperatriz (mapa 2), por meio de incentivos do governo estadual. Além disso, viu no espaço municipal potencialidades para sua instauração e funcionamento, tais como oferta de mão de obra para a construção inicial da fábrica, oferta de insumos necessários para o fabrico e presença de linha para escoamento da produção até o Porto de Itaqui. Também podemos considerar vantagens à oferta de universidades, centros de capacitação técnica, aeroportos, comunicação, serviços financeiros, ambiente empresarial e opções de consumo, que funcionam de forma combinada, ampliando a arrecadação fiscal da região.

Mapa - Localização do município de Imperatriz-MA

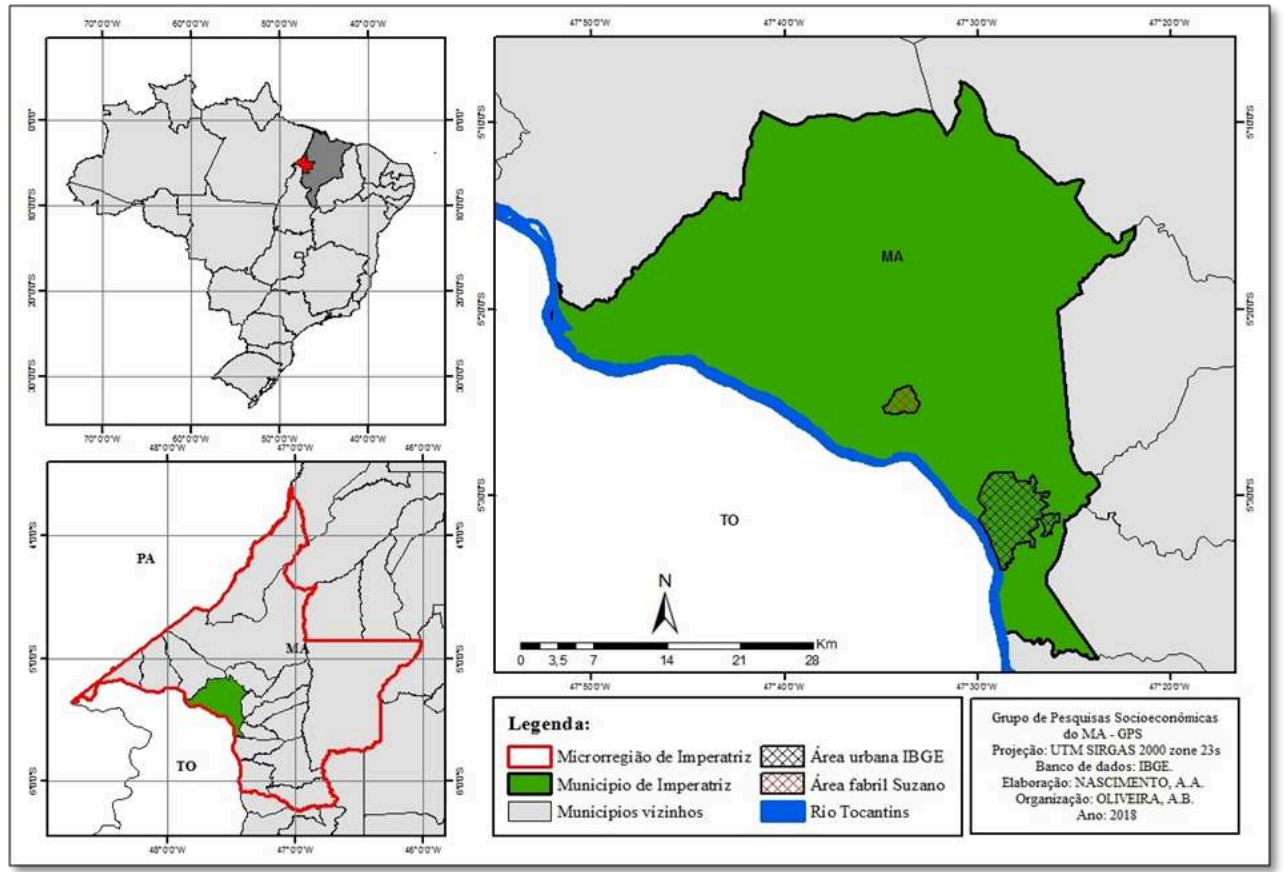

Fonte: Os autores (2018).

27 Assim, durante o período de instalação da fábrica, a cidade e a região circunvizinha foram reestruturadas para atender a uma nova ordem econômica. A linha ferroviária foi ampliada para melhorar o escoamento da produção a ser exportada; o acesso à fábrica por dentro da cidade - sendo essa a principal via de acesso, conhecida popularmente como "estrada do arroz" - foi pavimentado, e outro caminho, pela BR-010, foi criado para facilitar a entrada da matéria-prima (toras de eucalipto) vinda de municípios vizinhos.

Com a implantação da unidade fabril, seu desenvolvimento e a reestruturação do espaço urbano para atender à nova lógica dominante, outros elementos passaram a atuar em consonância com o novo cenário, tais como: a abertura de cursos em nível técnico e superior para atender às especificidades industriais; o aumento do setor de serviços para o fornecimento de produtos para toda a cadeia produtiva de papel e celulose; e a expansão do setor imobiliário, visando ofertar moradia para os migrantes 
laborais, tanto os que trabalharam na construção da fábrica, quanto os gestores que se mudaram para o município.

Conforme destaca Bessa (2005, p. 11):

O setor terciário é marcado, primordialmente, pela constituição do polo atacadodistribuidor, pela ampliação do consumo produtivo do campo, pelas modernas estruturas do comércio varejista, especialmente pela difusão dos supermercados, hipermercados e shopping centers, e pelas novas atividades associadas à prestação de serviços. Essas modalidades terciárias são responsáveis por um aumento quantitativo e qualitativo das interações espaciais, que passaram a ocorrer por meio da combinação de relações que se articulam em escalas local, regional e nacional.

Essa ampliação de opções de consumo é um reflexo da elevação de renda que modifica as características sociais oriundas da atividade industrial. Tal processo faz parte da nova urbanização, destacada por Santos (1993), segundo a qual o aumento da mão de obra cada vez mais qualificada faz surgir novos consumos e novas relações no espaço urbano.

Agências bancárias, redes hoteleiras, shoppings centers, voos comerciais, cabeamento de fibra ótica de internet e outros tipos de serviços técnicos se expandem para movimentar - agora sob nova demanda - o fluxo de capital que colabora nos processos de financiamento da sociedade e do território.

Todos esses fatores apresentados combinam-se para gerar uma ordem para os grandes atores hegemônicos e desordem para os demais. O espaço urbano é "convidado" a se reestruturar, se reorganizar para atender a uma demanda previamente definida: a circulação do capital, a produção fabril e a recepção da unidade fabril.Tal dinâmica será apresentará a seguir.

\section{Reestruturação urbana e investimentos em novas áreas residenciais: da implantação da indústria aos novos agentes imobiliários}

Das transformações mais visíveis - e também foco deste trabalho - destaca-se o aumento da malha urbana (Mapa 3), resultante do aumento demográfico de trabalhadores laborais e novos empreendedores dos segmentos da cadeia produtiva de papel e celulose, além de indivíduos de outras áreas, também atraídas para a cidade. Tais transformações ocorrem a partir da reprodução do capital intensificado pelas atividades industriais e das atividades comerciais, que se potencializam a partir da inserção de uma nova cadeia produtiva e novas necessidades locais.

Vemos assim uma transição das características econômicas do espaço urbano de Imperatriz. $O$ velho e o novo se confrontam a partir de mudanças paradigmáticas, em que antigas lógicas são suplantadas, dando lugar a novos arranjos sociais e econômicos. A predominância dos setores primário e terciário - até então prevalentes na atividade econômica da cidade de Imperatriz - dá lugar à instauração do setor secundário e à lógica que o segue. 
Mapa - Expansão da malha urbana a partir do ano de 2010

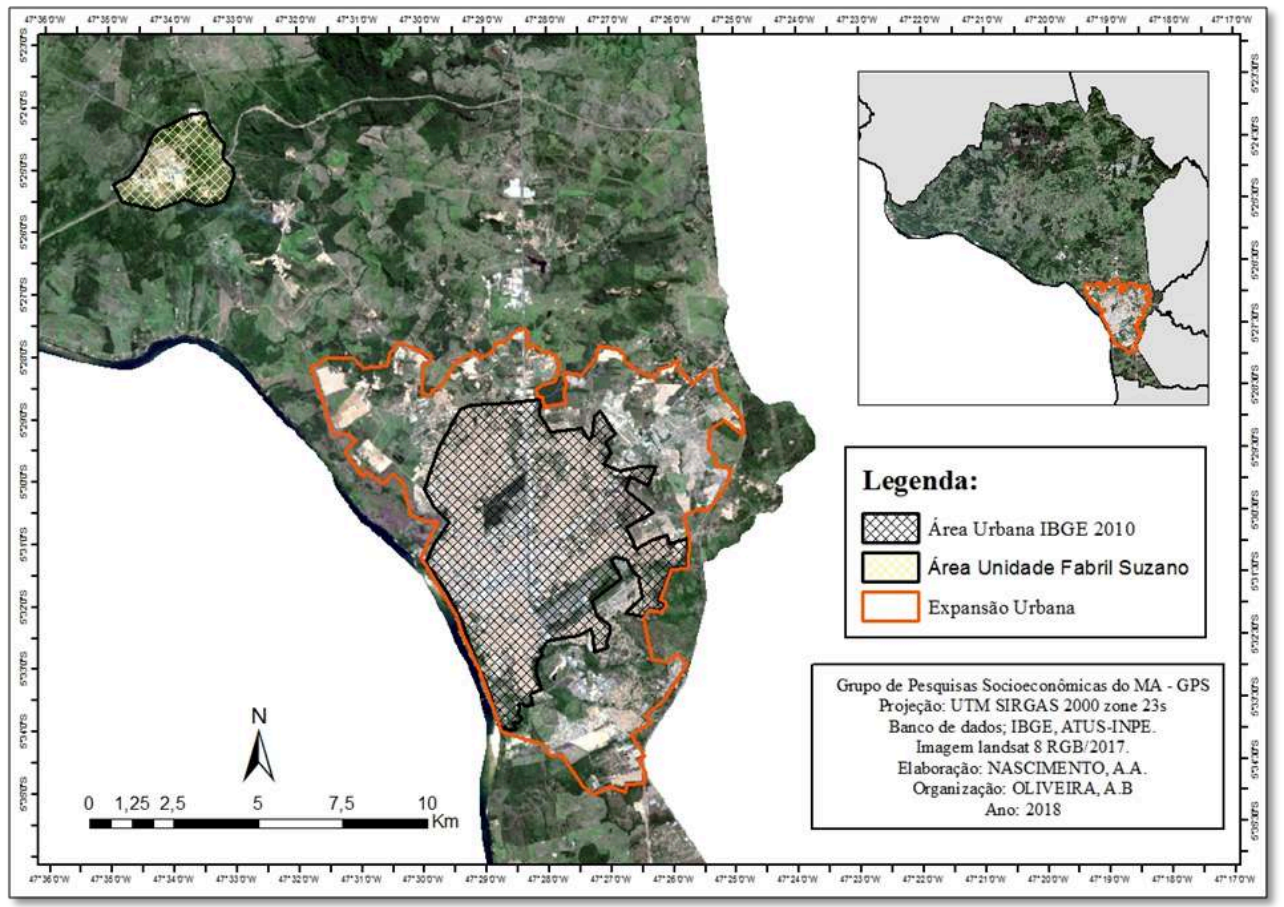

Fonte: Os autores (2018). urbana, representado pelo traçado de cor vermelha, em comparação ao traçado de cor preta, que representa a área urbana de 2010, correspondente ao período da implantação industrial. Tal aumento se deve ao significativo número de migrantes laborais que participaram da implantação da unidade fabril, além dos inúmeros novos segmentos da cadeia produtiva desencadeados por empresários ligados direta e indiretamente à empresa, o que também atraiu mais pessoas.

A atração de pessoas para novas atividades inseridas no contexto industrial e, consequentemente, o aumento do número de moradias e reestruturação urbana da cidade pode ser verificado em dados do IBGE (2016). Enquanto em 2007, ano anterior à construção da unidade fabril da Suzano, a população do município era de 229.671 pessoas, em 2010 esse número evoluiu para 247.505 e 253.873 em 2015. Cabe ressaltar que a cidade de Imperatriz detém expressiva centralidade urbano-regional em relação a uma série de municípios limítrofes que funcionam como cidades-dormitório para um contingente significativo de trabalhadores não contabilizados nos dados do IBGE.

anto demográfico decorre principalmente das ofertas de empregos geradas conforme a necessidade de profissionais para atuar em funções específicas na indústria. Foram abertas vagas para as áreas de comunicação, meio ambiente, TI, engenharias e química (para trabalhar diretamente com a produção de material celulósico) ${ }^{2}$. Como a cidade não possuía os profissionais necessários, com as qualificações exigidas, as vagas foram abertas para outros estados por meio de sites vinculados à empresa ${ }^{3}$.

Essa oferta de emprego faz parte do processo de modernização do espaço geográfico, que conta com alguns fatores atrativos e outros repulsivos, comuns ao processo de urbanização. É possível verificar essa dinâmica na história da industrialização brasileira com o caso da região Sudeste, que já foi forte ponto de atração de trabalhadores, 
requisitando força de trabalho para atender às demandas crescentes à época; depois de certo período, o mercado da região se viu saturado e com grande oferta de trabalhadores, mas não de trabalho.

Outro ponto importante é que esses grandes fluxos populacionais geram inchaços nos centros urbanos, uma vez que estes não possuem planejamento e estrutura para comportar o grande número de pessoas, que migra para as áreas periféricas, desqualificando o processo de urbanização. Seguindo esse decurso, em Imperatriz ocorreu uma valorização imobiliária e reorganização dos espaços existentes, além da criação de novas áreas para abrigar a população recém-chegada à cidade. Essas novas áreas encontram-se dentro da faixa de expansão da malha urbana (Mapa 3) que pode ser observada logo abaixo.

Mapa - Novas áreas habitacionais do município de Imperatriz-MA dentro da faixa de expansão urbana

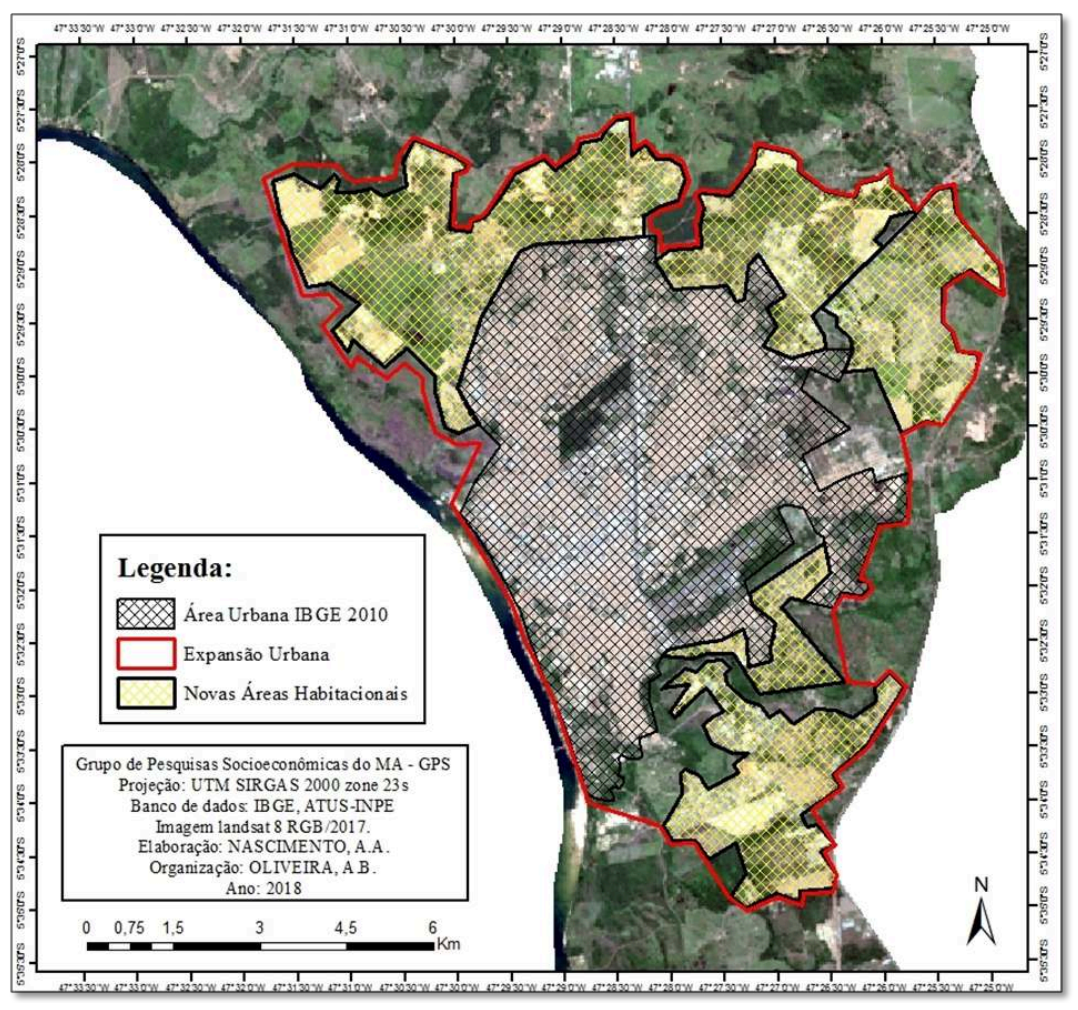

Fonte: Os autores (2018).

Para o surgimento dessas áreas habitacionais, alguns espaços passaram por adequações de terreno - no caso, pequenas áreas destinadas à agricultura de subsistência e pequenas fazendas deram espaço a loteamentos e condomínios horizontais. Além disso, bairros periféricos afastados receberam infraestrutura como pavimentação e iluminação, a fim de se tornarem mais atraentes para os consumidores dos empreendimentos que seriam construídos.

o levantamento em campo mostrou que a partir do empreendimento industrial na cidade, áreas afastadas passaram a ofertar opções de moradia. Temos, assim, em áreas ao longo da BR-010 e da Avenida Pedro Neiva de Santana, rumo ao município de João Lisboa, a construção de condomínios horizontais e loteamentos. Todos estes destinados às camadas populares com renda mínima de dois salários-mínimos 
Os anseios de consumo da nova dinâmica econômica da cidade incentivaram o crescimento das novas áreas habitacionais e do segmento de imóveis com custos médios de $\mathrm{R} \$ 130$ a 145 mil a unidade na planta. Os imóveis em questão podem ter até $90 \%$ do valor total financiados pelo programa do governo Minha Casa Minha Vida e ainda ter o valor de entrada pago com o FGTS. Assim, durante esta pesquisa listamos alguns dos empreendimentos criados nessas áreas, conforme quadro abaixo:

Quadro 1 - Empreendimentos populares

\begin{tabular}{|c|c|}
\hline Cidade jardim - loteamento & Ecopark I, II, III, IV, V e VI \\
\hline Cidade nova - loteamento & Gran Village I \\
\hline Parque Imperial - loteamento & Residencial Livia \\
\hline Verona - loteamento & Recanto dos Pássaros \\
\hline Athenas Park - loteamento & Morada dos Pássaros \\
\hline Terra dos Pássaros & Villa Real \\
\hline
\end{tabular}

Fonte: Elaborado pelos autores. Levantamento de campo, outubro de 2017.

Todos esses empreendimentos, acompanhando o crescimento econômico da cidade, passaram por transformações com altas no mercado. $O$ aumento da renda, a baixa inadimplência momentânea e a grande liberação do crédito imobiliário pelas instituições financeiras impulsionaram a supervalorização dos imóveis.

Visto o aumento dos custos de moradia para manter seus funcionários vindos de outros estados, a Suzano Papel e Celulose firmou parceria com a construtora Dimensão Engenharia para a construção de 120 casas distribuídas entre os condomínios Ecopark. As casas foram destinadas a funcionários de cargos operacionais e que preenchiam as seguintes exigências: ser casado, ter família e ser o único responsável pela renda familiar. Para funcionários de cargos executivos de coordenação e gerência, foram alugados imóveis em bairros centrais da cidade - Três Poderes e Maranhão Novo (Mapa 4) -, deixando claro que a separação hierárquica de funções de trabalho também é mantida do lado de fora dos muros da empresa. 
Mapa - Localização dos bairros nobres para construção de condomínios de alto padrão

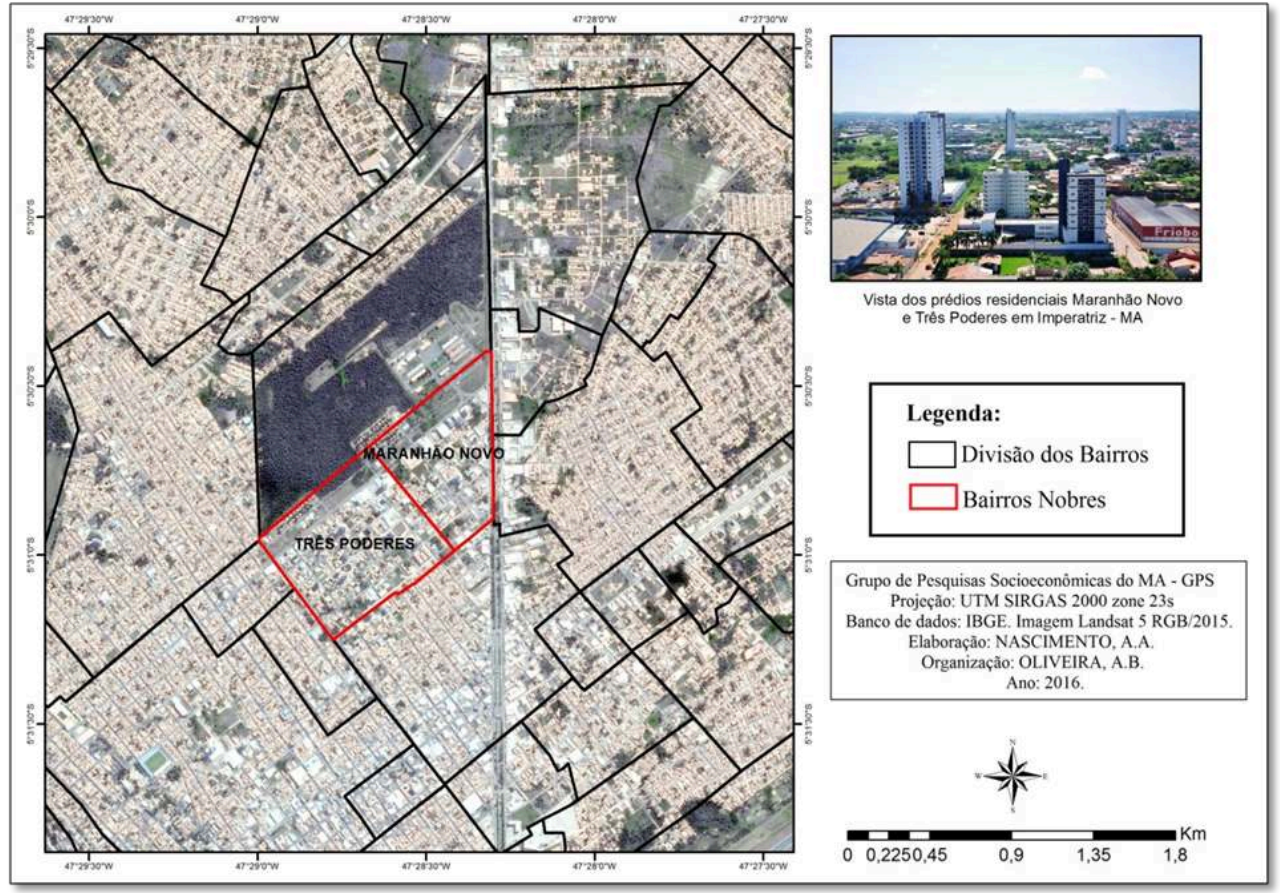

Fonte: Os autores (2017)

Os bairros destacados no mapa acima são considerados bairros nobres e concentravam, até então, mansões em sua paisagem. Hoje, os bairros passam por uma reestruturação, dando lugar a construções verticais de alto padrão (Quadro 2), comercializadas pelo valor de, no mínimo, $\mathrm{R} \$ 300$ mil a unidade.

Quadro 2: Empreendimentos de alto padrão

\begin{tabular}{|c|c|c|}
\hline Unique & Amazonas & Marina \\
\hline Primavera & Mediterranê Club & Twin Tower \\
\hline São Francisco & Moriah & Copacabana \\
\hline Maximus & Porto Real & River Side \\
\hline Grummary & Búzios & Varandas Norte \\
\hline Vitória Régia & Villagio Galdino & Mansões Paris \\
\hline Imperador Tocantins & Bela Vista & New Ville \\
\hline
\end{tabular}

Fonte: Elaborado pelos autores. Levantamento de campo, outubro de 2017.

Segundo dados das imobiliárias, além do aumento de construções residenciais, os valores de aluguéis aumentaram em 375\% para imóveis de até 3 quartos e $400 \%$ para imóveis de até 6 quartos, como pode ser observado no gráfico a seguir. Em meio à especulação imobiliária instalada, houve um particular processo de desocupação das casas pelos proprietários para que estas fossem alugadas para os vários agentes envolvidos na construção da unidade fabril, assim houve certa estruturação dos processos locatários no período: até 20 funcionários (pedreiros, serventes, eletricistas, encanadores etc.) alojados num mesmo imóvel, e até três funcionários (engenheiros, executivos, contadores, administradores etc.) em outros tipos de imóveis. 
Gráfico 2 - Especulação imobiliária a partir da implantação da Suzano Papel e Celulose em Imperatriz-MA

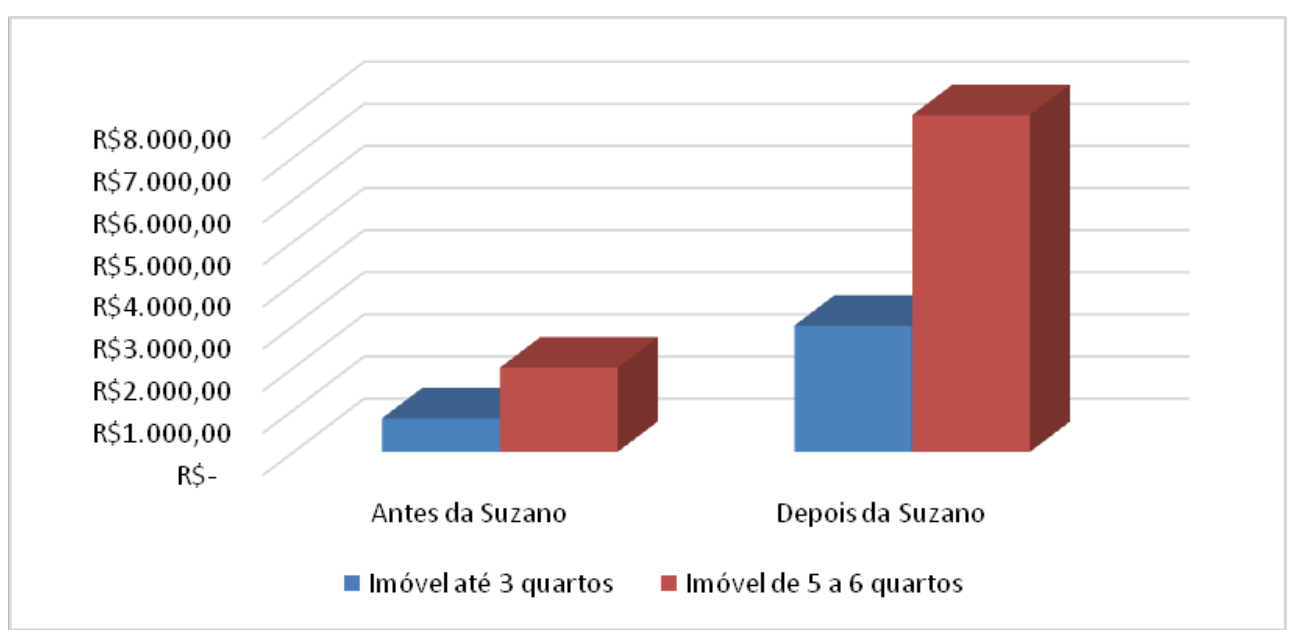

Fonte: Elaborado pelos autores. Levantamento de campo, novembro de 2016

Além dos atores diretamente ligados à unidade fabril, dos fornecedores da cadeia produtiva e de imobiliárias, também outros atores são atraídos para se instalar na cidade e contribuir com a nova lógica predominante de reprodução do capital. Nessa multiplicidade de ações e objetos, hotéis, centros comerciais, centros médicos e universidades foram implantados para atender às novas demandas.

Quadro 3: Empreendimentos comerciais, empresariais e universidades criadas (2008-2015)

\begin{tabular}{|c|c|}
\hline Tocantins Shopping & Ibis Hotel \\
\hline Imperial Shopping & Imperatriz Residence Hotel \\
\hline Centro de compras GV & Imperial Hotel \\
\hline Hospital das Clinicas & Stay Inn Hotel \\
\hline Medical Center & Universidade Ceuma \\
\hline Aracati Office & Faculdade Pitágoras \\
\hline
\end{tabular}

Fonte: Elaborado pelos autores. Levantamento de campo, novembro de 2016

Cada um desses empreendimentos viu nas necessidades geradas pela indústria uma oportunidade de lucro. Surgiram novos profissionais e novas fontes de renda, modificando as características sociais e culturais da cidade (BESSA, 2005). Assim, temos a criação de serviços para atender à mudança de consumo da população residente. Esse novo cenário argumenta-se nas teorias de Santos (1993), implica maior concentração de trabalho intelectual, novos consumos e novas relações no espaço.

\section{Considerações finais}

As considerações neste trabalho apresentadas, em conjunto com os dados coletados, contribuem para a compreensão da clara e inequívoca relação entre a reestruturação do espaço urbano de Imperatriz frente a implantação da unidade fabril da Suzano Papel e Celulose. Tal relação Indústria x espaço urbano é clássica nos estudos da ciência geográfica, e tem fornecido subsídios importantíssimos nas compreensões sobre as dimensões econômicas das cidades. 
50 Nesta breve compreensão, o espaço urbano, dentro da lógica da implantação industrial, vem a ser a base fundamental que generaliza e transforma as dinâmicas de reprodução do capital e consequentemente proporciona a gênese da atividade industrial em estudo. Sistemas de Objetos e Sistemas de Ações neste sentido, são, (re)organizados para atender um processo econômico em curso que, embora tenha sua principal base de implantação e produção o espaço agrário, depende fortemente do espaço urbano para que possa funcionar em consonância com os modelos concorrenciais das economias de escala em um mercado cada vez mais global.

51 Em especial para o recorte deste trabalho, a implantação industrial da unidade fabril da Suzano Papel e Celulose, atende a um modelo de desconcentração deste tipo de atividade para regiões mais periféricas, em busca de terra barata e outros recursos naturais em abundância. Porém, embora a base para a produção e a própria implantação fabril seja o espaço agrário, o espaço urbano fica fortemente condicionado e subordinado às atividades ali em curso. A cidade de Imperatriz, em meio às transformações aqui apresentada viu em um período de tempo extremamente curto, uma reestruturação de seu espaço urbano para atender um contingente temporário e definitivo de migrantes laborais para atuar na fábrica.

Tal processo vem acompanhado de extrema especulação imobiliária pelos agentes que envolvem a cadeia de produção de papel e celulose. Novas estruturas, formas e processos são constituídos para atender a lógica econômica predominante. $\mathrm{E}$ estas por sua vez são extremamente baseadas na especulação da terra. A terra enquanto base material do espaço urbano se torna elemento especulativo na expansão da malha urbana, nas formas de moraria e nos novos valores incorporados. Assim, há uma lógica em curso que instaura uma lógica para a fábrica e caos para a cidade.

\section{BIBLIOGRAPHY}

AMORIM FILHO, O.B; SERRA, R.V. Evolução e perspectivas das cidades médias no planejamento urbano e regional. In: ANDRADE, T; SERRA, R.V. (orgs). Cidades Médias Brasileiras. Rio de Janeiro: IPEA, 2001.

ASSOCIAÇÃO BRASILEIRA DE CELULOSE E PAPEL - BRACELPA. Relatório estatístico da BRACELPA. São Paulo, 2000-2010.

BESSA, Kelly Cristine. Reestruturação da rede urbana brasileira e cidades médias: o exemplo de Uberlândia (MG). Revista Caminhos de Geografia 24 (16) 268-288, out/2005.

BOTELHO, Adriano. Reestruturação produtiva e produção do espaço: o caso da indústria automobilística instalada no Brasil. Revista do departamento de Geografia, 15 (2002). P.55-64.

BRASIL. Região de Influência das Cidades - REGIC, 2007. Disponível em: http://www.mma.gov.br/ estruturas/PZEE/_arquivos/regic_28.pdf .Acesso: 26/01/2018.

CALDEIRA, Teresa Pires do Rio. Cidade de Muros. São Paulo: Edusp, 2000. 
CANO, W. Raízes da concentração industrial em São Paulo. $2^{\text {a }}$ Edição - São Paulo: T.A. Queiroz. 2008.

CARVALHO, Sheryda Lila de Souza; OLIVEIRA, Adão Francisco de. Condomínios horizontais em espaços periféricos: reflexões sobre a realidade de Imperatriz (MA). Anais do XI - ENANPEGE 2015.

CORRÊA, Roberto Lobato. O Espaço Urbano. São Paulo: Ática, 2004.

CHRISTALLER, Walter. Central Places in Southern Germany. New Jersey: Prentice-Hall, (Trad. C.W. Baskin). 1966.

GOMES, Maria Tereza Serafim. Cidades médias, novos espaços produtivos e reestruturação do espaço urbano de Uberaba-MG. CONFINS: Revista Franco Brasileira de Geografia. № 25, 2015.

LEITE, Elenice M. Reestruturação industrial, cadeias produtivas e qualificação. In: Reestruturação produtiva e mercado de trabalho no Brasil. CARLEIAL, Liana \& VALLE, Rogério (org). Hucitec: São Paulo, 1997.

SANTOS, Milton. A urbanização brasileira. São Paulo: Hucitec, 1993.

SANTOS, Milton. \& SILVEIRA, Maria Laura. O Brasil: território e sociedade no início do século XXI. Rio de Janeiro: Record, 2001.

SILVA, Valéria Ferreira da; CALIXTO, Maria José Martinelli Silva. As cidades médias enquanto importante nó na rede urbana: uma análise da cidade de Dourados-MS. Ano 2012.

SOARES, Paulo Roberto Rodrigues; AMARAL, Stella Maris Ricardo do. Reestruturação do espaço urbano: a produção capitalista de moradias em Rio Grande/RS (Os condomínios verticais). Boletim Gaúcho de Geografia, 22:53-61. Março, 1997.

SPOSITO, M.E.B (org). Cidades Médias: espaços em transição. São Paulo: Expressão Popular, 2007.

SUZIGAN, W. Indústria Brasileira: origem e desenvolvimento. São Paulo: Hucitec, Ed. Da Unicamp, 2000.

\section{NOTES}

1. Versão gratuita disponível para download: www.arcgis.com.

2. Informações coletadas no Painel Florestal. Disponível em: www.painelflorestal.com.br.

3. Catho e Vagas.com são os sites oficiais vinculados à empresa. Neles, a Suzano disponibiliza vagas de emprego e programas de estágio, ficando visíveis para todo o Brasil.

4. Renda mínima exigida pelo programa de financiamento do governo federal Minha Casa Minha Vida.

\section{ABSTRACTS}

The paper aims to discuss some of the most relevant urban space restructuring processes that occurred during 2008-2015, triggered by the establishment of a Suzano Papel e Celulose factory in 
Imperatriz, located in Maranhão state. From interviews and cartographic production, we aimed to register transformations in the urban space of the city to attend to the emergence of a new industrial logic as well as the economic agents attracted by the factory establishment. The results display that the factory implantation was followed by restructuring and requalification of the city districts, promoting verticalization, real state speculation and expansion of the urban area.

O presente artigo tem como objetivo principal discutir alguns dos mais relevantes processos de reestruturação do espaço urbano ocorridos no período de 2008-2015, desencadeados pela implantação de uma unidade fabril da Suzano Papel e Celulose no município de Imperatriz, localizado no estado do Maranhão. A partir de dados secundários, entrevistas e produção cartográfica, buscou-se verificar as transformações no espaço urbano do município empreendidas para atender à emergência de uma nova lógica da indústria e dos vários agentes econômicos atraídos pelo estabelecimento da fábrica. Os resultados apresentados apontam que a implantação industrial tem sido acompanhada de reestruturação e requalificação dos bairros da cidade, promovendo processos de verticalização, especulação, supervalorização imobiliária e expansão da malha urbana.

El presente artículo tiene como objetivo discutir los aspectos más relevantes del proceso de reestructuración del espacio urbano entre 2008 - 2015, generados por la implantación de la fábrica de Suzano Papel y Celulosa. A partir de fuentes secundarias, entrevistas y cartografía se verificaron las transformaciones del espacio urbano en el municipio emprendidas para atender la lógica de la industria y de varios agentes económicos atraídos por la introducción de la fábrica. Los resultados muestran que la implantación industrial fue acompañada por una transformación de los barrios de la ciudad, promoviendo procesos de verticalización, especulación, plusvalía inmobiliaria y expansión del área urbana.

Cet article vise en premier lieu à débattre de certains des principaux processus de restructuration de l'espace urbain survenus entre 2008 et 2015, déclenchés par l'implantation d'un établissement industriel appartenant à Suzano Papel e Celulose, dans la commune d'Imperatriz, située dans l'État de Maranhão. À partir de données secondaires, d'entretiens et de cartes, on a cherché à vérifier les transformations survenues dans l'espace urbain de la commune, pour répondre à l'émergence d'une nouvelle logique industrielle à laquelle obéissent divers acteurs économiques, attirés par l'implantation de l'usine. Les résultats de cette étude montrent que l'implantation de l'usine s'est accompagnée d'une restructuration et d'une requalification des quartiers de la ville, favorisant un processus de verticalisation, de spéculation, de survalorisation immobilière et d'expansion du tissu urbain.

\section{INDEX}

Mots-clés: restructuration de l'espace urbain, Suzano Papel e Celulose, Imperatriz-Maranhão Keywords: restructuring of urban space, Suzano Papel e Celulose (paper company), ImperatrizMA.

Palavras-chave: reestruturação do espaço urbano, Suzano Papel e Celulose, Imperatriz-MA. Palabras claves: reestructuración del espacio urbano, Suzano Papel e Celulose, Imperatriz-MA.

\section{AUTHORS}

\section{ALLISON BEZERRA OLIVEIRA}

Professor 
Universidade Estadual da Região Tocantina do Maranhão - UEMASUL

Grupo de Pesquisas Socioeconômicas do Maranhão - GPS

allisonbzr@gmail.com

\section{AMANDA ARAÚJO NASCIMENTO}

Graduanda do curso de Geografia da Universidade Estadual da Região Tocantina do Maranhão UEMASUL

Grupo de Pesquisas Socioeconômicas do Maranhão - GPS

amanda_nasci@hotmail.com 